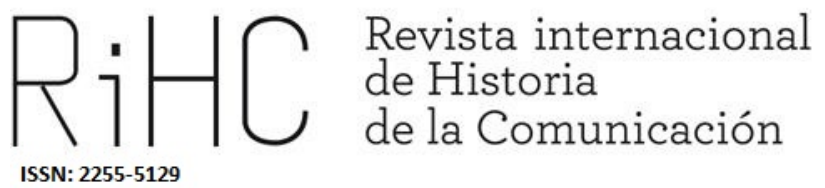

\title{
LA INFORMACIÓN DE SUCESOS EN UN PERIÓDICO ISABELINO: LOS SUCESOS (1867-1868)
}

\section{The events news in an Elizabethan newspaper: Los Sucesos (1867-1868)}

DOI: http://dx.doi.org/10.12795/RiHC.2018.i10.10

Recibido: 06/01/2018

Aceptado: 05/04/2018

Publicado: $25 / 06 / 2018$

Víctor José Ortega Muñoz (D) https://orcid.org/0000-0002-8472-4414

Universidad de Málaga, vjortega@uma.es

Resumen: Vamos a estudiar el periódico "Los Sucesos", centrándonos en las informaciones de sucesos. A parte del interés que pudiera tener dentro del marco de la Historia de la Prensa, a través de las mismas observaremos la cuestión social y como la tensión se irradia desde y hasta los sectores populares de la sociedad.

Palabras clave: Prensa, Sucesos, Historia Social, España Isabelina.

Abstract: We are going to study "Los Sucesos" newspaper, focusing on events news. Part of the interest within the framework of the History of the Press, through them we 
are going to observe the social issue and how the tension radiates from and to the popular sectors.

Keywords: Press, Event news, Social History, Elizabethan Spain.

\section{Introducción}

Este estudio analiza Los Sucesos, ${ }^{1}$ uno de los periódicos del periodista Ángel de los Ríos, que destaca por su variedad temática, su apoliticismo, la inclusión de ilustraciones como complementos de las noticias y la presencia de noticias diversas como los sucesos.

Pocos dudan de la importancia que atesora la prensa y su estudio, no solo para la historia de la prensa, sino para la historia en general, cosa distinta son aquellas reseñas sensacionalistas, olvidadas y consideradas poco más que curiosidades sin interés. Dentro del amplio espectro que conforman dichas informaciones cobran especial protagonismo los llamados sucesos, tradicionalmente ignoradas por los investigadores a pesar de su interés para el estudio social de lo que ocurre o acontece en la calle. Recordemos las palabras de Tuñón de Lara:

...la prensa es de valor inapreciable. Pero en otras secciones que aquellas que suelen ser objeto de nuestra predilección. Se trata de los reportajes, de los sucesos, de los anuncios, de los espectáculos, de las crónicas de sociedad. (Tuñón, 1973: 140).

La prensa, en su labor de selección y exposición de aquello que se estima noticiable construye una representación del mundo, cuya comprensión en los elementos en que se sustenta requiere recopilar la mayor cantidad de información posible:

Es lo que el profesor Kayser denomina la "personalidad" el periódico y que nosotros conocemos por el nombre de "biografía técnica" del diario. Se trata de obtener el mayor número posible de información que permita elaborar unos datos precisos y racionales sobre la marcha interior del diario y sobre aquellos elementos, que si bien suelen pasar desapercibidos para el público lector, resultan de un interés extraordinario para el especialista. (Casasús, 1998: 105)

En esta construcción del discurso que se elabora a través de los diversos enfoques noticieros no debemos olvidar la existencia ya de una opinión pública cuya importancia, real o supuesta, va a ser protagonista de los diarios. Este nuevo concepto

\footnotetext{
${ }^{1}$ Unos años después (noviembre 1882) surgirá la, según Rodríguez Cárcela, primera publicación especializada de la que existe constancia en el siglo XIX, que llevará el mismo nombre Los Sucesos. Revista ilustrada de actualidades, siniestros, crímenes y causas célebres, ver (RODRÍGUEZ, 2016: 22:44).
} 
se convertirá en elemento legitimador para las posiciones que se defienden, en un principio desde el ámbito político. Se realizan apelaciones intensivas a la opinión pública en estos momentos de zozobra política (Capellán, 2010:50), para más adelante englobar otros aspectos de relevancia social.

Igualmente, debemos tener presente las precauciones propias de aquellos que se acercan a unos relatos que ya de por si ofrecen un sesgo negativo para sus protagonistas, dado el cariz de los hechos narrados. Tampoco olvidamos la posibilidad de que existan noticias si no directamente falsas, si exageradas en la búsqueda de una atención que favorezca la venta de ejemplares. Obligándonos a utilizar constantemente un punto de vista en el que no nos dejemos deslumbrar y empleando siempre la crítica.

En el caso de España, coherente con el clima de agitación política y, descubiertas las posibilidades de la prensa para influir en la opinión pública, se observan grandes cambios tanto en el aspecto funcional como en la forma y estructura. De forma que a finales del siglo XIX distinguimos ya una prensa semejante a la actual. La prensa isabelina se caracteriza por la multiplicidad de cabeceras de breve existencia, la escasez de datos estadísticos y, en muchas ocasiones, una deficiente conservación que impide una comprensión adecuada. "Los datos estadísticos disponibles sobre los medios informativos, la publicidad, las tiradas y la audiencia de periódicos y revistas no permiten seguir con bastante precisión la evolución del mercado de la prensa, de sus grandes categorías de publicaciones y de sus principales títulos, hasta un pasado muy cercano" (Guereña, 1982: 81). Centrando nuestra atención sobre la publicación de diarios en Málaga:

El periodismo anterior a la Restauración se desenvolvió en Málaga, al igual que en el resto del país, en circunstancias poco propicias, que limitaron lógicamente su desarrollo y retrasaron su transformación. Las condiciones jurídico-políticas del país no eran favorables, debido a la inestabilidad de la política nacional que mantenía una libertad de expresión en límites generalmente poco permisivos, y que reflejaba el enfrentamiento que subyacía en la sociedad española entre los distintos sectores de la burguesía. (García Galindo, 1995: 16)

A finales del reinado de Isabel II aparece el periodismo de noticias en parte gracias al desarrollo de diversas tecnologías, principalmente el ferrocarril y el telégrafo. Éstos permitieron una rápida difusión de un número cada vez mayor de ejemplares, así como la recepción de noticias desde lugares lejanos y con una inmediatez nunca antes conocida. Este nuevo periodismo tendrá entre sus primeros representantes cabeceras como La Correspondencia [1860], que fueron criticadas por sus colegas de la prensa política. En un principio advirtieron en éstas una peligrosa innovación por su pretensión de imparciales sin implicarse en el panorama político. A su vez Las Novedades (1850), fundado por Ángel Fernández de los Ríos, fue el primer periódico 
noticiero exitoso cuya temática unida al precio popular, lo situaron en el primer puesto por tirada y circulación a los cuatro años de su fundación, puesto que mantendrá durante diez años consecutivos y del cual sólo será despojado con la aparición de La Correspondencia de España (1859) (Seoane, 1977: 272-273).

Siguiendo la figura de este editor, nos encontramos ante uno de los personajes más dinámicos y activos del siglo XIX, cuya vida ejemplifica como ninguna la vitalidad e incertidumbres de la empresa periodística. Nacido en Madrid en 1821, será en 1841 cuando Ángel Fernández de los Ríos se introduce en el mundo periodístico trabajando como redactor de El Espectador. Posteriormente, en el periodo que abarca desde 1845 a 1860 llegó a dirigir El Siglo Pintoresco, después La Ilustración y más tarde el Semanario Pintoresco Español, dirección esta última que simultaneó con la de Las Novedades (1850-1858). Funda finalmente Los Sucesos en 1866, en cuyos dos primeros meses de existencia alcanzó los 7.000 suscriptores, aunque se ve obligado a abandonarlo al emigrar a París tras su participación en la sublevación del cuartel de San Gil en junio de 1866, por el peligro de muerte ante un Consejo de Guerra (Alonso, 2002: 140). Dada la implicación política de Fernández de los Ríos, siempre comprometido con sus ideas, sorprende el apoliticismo de ésta última cabecera, más teniendo en cuenta que a la vez participaba en publicaciones progresistas y republicanas desde el exilio (Del Río, 2016: 60). La muerte le llegó en París en junio de 1880, a través de unas fiebres tifoideas, aún exiliado pero no olvidado (Ibídem).

\section{Los Sucesos: precedente de un modelo de prensa popular}

Durante el corto espacio temporal de su publicación pasó por dos imprentas, primeramente, fue impreso en la de $M$. Tello y después se trasladó a un establecimiento tipográfico propio. Comenzando su andadura el 2 de octubre de 1866 y terminando el 15 de mayo de 1869, con un total de 1.839 ejemplares publicados (Hartzenbusch, 1993). Aquellos que han sido estudiados se corresponden a los depositados en los fondos de Archivo Díaz Escovar, ${ }^{2}$ que presenta una serie incompleta formada por 169 ejemplares que abarca desde el 11 de septiembre de 1867 al 23 de octubre de 1868. La falta de conservación de un número mayor nos inclinó al estudio de toda la serie conservada, analizando todas las informaciones de sucesos, de las cuales incluimos aquí aquellas que consideramos representativas.

\footnotetext{
${ }^{2}$ Accesible por internet en la dirección http://www.archivodiazescovar.com, el Archivo Díaz Escovar del Museo Unicaja de Artes y Costumbres Populares es público, de la Fundación Unicaja e integrado por los fondos bibliográficos de Narciso Díaz de Escovar, escritor, abogado y periodista malagueño.
} 
También nos proporciona Hartzenbusch la lista de los redactores que trabajaron en el mismo:
Avial (D. Pedro).
Avilés (D. Ángel).
Bona (D. Félix Javier).
Bona (D. Francisco Javier).
Díaz Pérez (D. Nicolás).
Hernando (D. Francisco).
Inza (D. Eduardo de).
Prieto y Prieto (D. Manuel).
Raymundo (D. Pedro Francisco).
Saco (D. Eduardo), y otros señores.

Destaca en su vertiente visual a la vez que se creó con los siguientes objetivos: "LOS SUCESOS, durante el período de tiempo que cuenta de existencia, ha logrado cumplir el fin que se propuso desde que vio la luz pública, siendo el periódico de las familias, el guía del hogar doméstico, el consultor del industrial y el índice razonado de todos los acontecimientos que se han verificado en el mundo". ${ }^{3}$ El mismo medio recalcará que las modificaciones que va a acometer ya desde sus inicios, que tienen un coste económico para el periódico, no repercutirá en el precio de suscripción, que se mantendría como sigue: Madrid: Un mes 8 rs.-Provincias: Trimestre, 30.- Girando contra los suscriptores, 36.- Ultramar y extranjero: 50 , precios casi sin variaciones 0 variaciones muy pequeñas durante el periodo estudiado.

Las medidas reales de las cuatro páginas de las que constaba el periódico, eran de 0,37 x 0,266 m, a cuatro columnas. Particularmente la estructura formal de Los Sucesos destaca por su cabecera, la cual se mantendrá durante todo el periodo consultado y que ya desde el primer vistazo expone qué podemos esperar de él. Prioriza el nombre del periódico en grandes caracteres, aunque no es el único texto que encontramos, ya que ofrece información sobre los días de publicación y lemas como por ejemplo "describe y dibuja", "ojeada universal" y "Fiat lux". A lo cual se le suma la rica decoración de la misma, que se encamina hacia un mismo sentido universalista y así encontramos por ejemplo las pirámides de Egipto, un globo aerostático, el Congreso

\footnotetext{
${ }^{3}$ Los Sucesos, 3/1/1868, no 385
} 
de los diputados, ánforas, el globo terráqueo, etc. Todo un despliegue iconográfico para atraer al lector desde el principio.

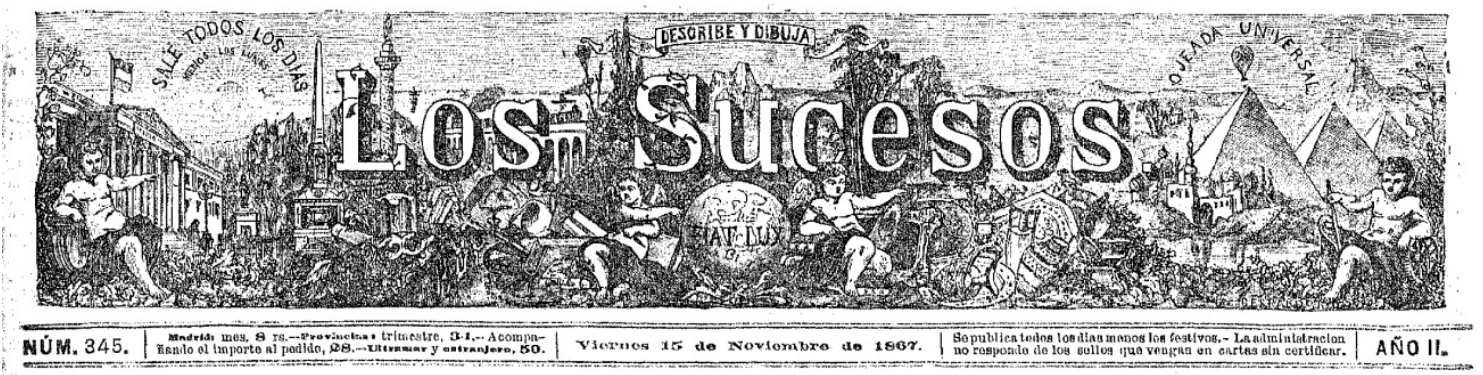

En la primera de las cuatro páginas suele aparecer un grabado de mayor o menor tamaño (media página e incluso a veces la página entera) que tiene como compañeros a otros grabados (o grabado, el tamaño y el número varía en cada ejemplar) en la última página. Esta estructura se mantiene salvo casos excepcionales en que se publica un grabado de gran tamaño que ocupa las dos páginas centrales, en cuyo caso solo aparece éste y, por tanto, el número de noticias disminuye. Si dirigimos nuestra mirada a la temática de los grabados, destaca su variedad, aunque es posible notar que los grabados de la última página suelen ser mayoritariamente de maquinaria agrícola y avances tecnológicos; igualmente encontramos otros tipos de motivos como viñetas humorísticas, lugares, personalidades, rarezas... Entre los grabados de la portada encontramos retratos de personas ilustres, hasta representaciones de uniformes militares, pasando por lugares famosos, escenas costumbristas, etnografía, edificios, representación de alguna noticia, etc.

Al grabado de la primera página le suele acompañar, con el título de GRABADOS, una explicación de la ilustración. Aparte de la cabecera y el grabado nos encontramos en la segunda página una serie de artículos de gran extensión, con una temática de lo más variopinta. Así, podemos encontrar que se nos habla de temas como la educación, la vivienda de los obreros, astronomía, historia, biología, agricultura, geología, literatura, información detallada sobre una provincia española, química, religión, moral y un largo etcétera.

Además, esta es la página donde se incluye el folletín, una novela por entregas que trata de llamar y mantener la atención del lector de modo que la trama obligue a la compra diaria del ejemplar para ir conociendo el desarrollo de la historia y su desenlace.

La tercera página reúne pequeñas noticias variadas, recogidas usualmente bajo el título de "Sucesos Varios". Encontramos la sección "Sucesos el Exterior", en la cual se 
recogen una serie de noticias, generalmente cortas y de temática política, de lo sucedido en el extranjero, éstas noticias serán suministradas durante un tiempo por la agencia Fabra, en otros momentos no se menciona el origen o procedencia, lo que nos hace pensar que son obtenidas a través del telégrafo. También suele aparecer en esta página y con un carácter fijo la sección "Sucesos del día", donde se reúnen pequeñas noticias de todo tipo que han sucedido por lo general en el territorio español. Suele acompañar con menor o mayor extensión, aunque sujeto al espacio disponible, un apartado de "Teatros" donde se hace una crítica de las obras que se están representando y sobre los actores que las interpretan. También localizamos información de servicios, sobre los astros (hora de salida y puesta del Sol y la Luna), el santoral, las efemérides, información sobre la bolsa y espectáculos (lugar, hora y espectáculo existente en Madrid). Hubo un momento, con la adquisición del carácter de político que hizo incluir un nuevo contenido en el periódico, información sobre las sesiones del Congreso y el Senado, pero limitándose a una breve crónica que acabará desapareciendo.

Por último encontramos la cuarta página. Ya hemos mencionado el grabado que acompaña a una serie de noticias o artículos cortos sobre variedades, abundando aquellas más llamativas o dadas al humor. También encontramos anécdotas, consejos prácticos de bricolaje, cocina, etc., poemas, epigramas y algún pasatiempo, entre los cuales destaca la charada, aunque también podemos llegar a encontrar en algunos números jeroglíficos y salto de caballo. Para finalizar con el contenido de esta página no nos podemos olvidar de la publicidad, que ocupa la mitad inferior de la misma.

En Los Sucesos localizamos artículos de opinión y noticias de sucesos. Los primeros aparecen en las dos primeras páginas de cada ejemplar y se caracterizan por una mayor extensión, la descripción y los análisis de un tema desde un punto de vista determinado, coincidente con los gustos y opiniones burgueses del momento. Por el contrario, las noticias de sucesos suelen ocupar pocas líneas ${ }^{4}$ y se caracterizan por enunciar el hecho acontecido, el lugar, los protagonistas (no siempre) y las consecuencias. No olvidemos que hasta el momento no ha existido una división muy clara de los artículos y tampoco se identificaban rotundamente con titulares. Es por ello que las reseñas de sucesos, en el sentido que las conocemos hoy, no ocupan un número cuantioso de cada ejemplar, estando en torno al $5 \%$ del espacio informativo y variando en cada número.

\footnotetext{
${ }^{4}$ Debemos matizar la extensión en líneas de las informaciones de sucesos, pues si bien por lo general son pocas en comparación con otros artículos, presentan una extensión considerable si lo ponemos en relación con la que tendrán en periódicos posteriores como La Vanguardia o La Unión Mercantil. Ver (ORTEGA: 2018)
} 
Con el paso de los meses y enmarcada en una estrategia de claridad que podemos apreciar en la aparición de proto-secciones, también observamos un mayor uso mayor de títulos para identificar la temática de la noticia.

Por último debemos resaltar el papel que va adquiriendo la publicidad, de vital importancia para la empresa periodística, pues la financiación que proporciona paga gran parte de la publicación y permite abaratar los precios para atraer a más lectores, aunque en el caso de España se encuentre con la limitación que impone la elevada tasa de analfabetismo y la enorme capa de pobreza que cubría a la mayor parte de la sociedad.

\subsection{Cuestión social y beneficencia}

Durante el periodo isabelino (1833-1868) asistimos a un empeoramiento en las condiciones de las clases más pobres, cuyo número aumentará. Entre las razones de este incremento podemos citar las desamortizaciones de Mendizábal y Madoz, que habrían perjudicado a parte del sector agrícola. El campo envía una enorme cantidad de mano de obra a la ciudad que la industria española no es capaz de absorber, creándose capas marginales cuyas necesidades básicas no van a estar cubiertas y son caldo de cultivo de tensiones y rebeliones. Para tratar de evitarlo la burguesía se hará cargo de la función caritativa, que durante el Antiguo Régimen había estado exclusivamente en manos de la Iglesia, como una forma de mantener el statu quo.

Los artículos sobre la beneficencia y la miseria, la llamada cuestión social, son abundantes y en ellos se argumentan las causas y las posibles actuaciones caritativas para su solución. Así se incentivan las prácticas piadosas mediante afligidos relatos sobre familias desamparadas, niños hambrientos obligados a trabajos inmundos, etc. que tratan de conmover y promover la actitud cristiana de ayuda al prójimo. "[...] En todo caso, lo que se buscaba era seguir potenciando esa visión que aludía a la bondad de la pobreza y la obligada resignación que debían mostrar los sectores más desfavorecidos de la sociedad" (Crespo, 2016: 94).

Más allá de la solidaridad, ${ }^{5}$ la función de la beneficencia es reproducir y asegurar la mano de obra evitando el incremento de delincuentes que atenten contra la propiedad o la integridad física. La idea era que los malhechores del mañana son los niños del presente, por lo que, si se cuidan sus condiciones y educación, se puede evitar la criminalidad. Es por ello que la beneficencia se va a centrar sobre todo en los niños.

\footnotetext{
${ }^{5}$ La solidaridad puede aparecer especialmente en casos de catástrofes naturales, como ya estudiamos para el caso de prensa durante la Restauración: (ORTEGA, 2014: 509-520).
} 
Por otra parte, la petición de limosna va a ser vista de diversas maneras. Que se pida para la manutención familiar en momentos de necesidad cuando escasea el trabajo, se ve digno de elogio, siendo lo correcto socorrerles. Diferente es el caso de los falsos mendigos, gente ociosa que no tiene ganas de trabajar y que pretende ganarse el jornal a costa de los buenos sentimientos de la gente. Estos timadores, en la terminología de la época, son mal vistos y se previene contra ellos.

Además de la beneficencia particular, la que se ejerce de forma individual, existe otra estatal apoyada en instituciones como comedores, salas de expósitos, comedores populares, y asociaciones de todo tipo, "generalmente dirigidas por la nobleza y supervisadas por el clero, mantienen asilos y colegios o reparten periódicamente raciones de comida y vestidos en los barrios populares. Además, el burgués a la hora de la muerte reserva parte de su herencia para obras benéficas, que la prensa de la época machaconamente se encarga de airear" (Bahamonde, 1978: 47). Así no es de extrañar que encontremos en Los Sucesos numerosas noticias, generalmente de carácter breve, que informan cumplidamente de las labores de beneficencia.

Se diferencia el tipo de beneficencia por género; así mujer y beneficencia van a ser dos palabras íntimamente ligadas durante el siglo XIX. Las mujeres se encargaban de participar en asociaciones benéficas, aportando en dicha tarea sus características naturales de dulzura, sensibilidad... Se trataba de convencer de las virtudes de la caridad ejercida por la mujer, entendida ésta en el más amplio sentido de la palabra: no basta con dar una cantidad de dinero al desvalido y olvidarse pensando que ya todo está hecho, sino que a veces es más necesaria una mirada amiga, una caricia a tiempo, comprensión ante el dolor y la situación. Fortaleciendo el estereotipo femenino y el sistema patriarcal de organización social.

\section{La Búsqueda de la respuesta del lector}

En un principio, debemos tener en cuenta que:

La información de sucesos es muy variada y compleja. Recoge contenidos de temáticas diferentes, pero reconocibles en la mayoría de los casos, ya que mayoritariamente son malas noticias: la comisión de delitos y faltas, las catástrofes naturales, los siniestros y los comportamientos humanos conflictivos o violentos. Asimismo, son sucesos todos aquellos hechos curiosos, sorprendentes o extravagantes que se salen de la norma habitual (Rodríguez Cárcela, 2011: 310). 
Así, un periódico de sucesos, como indica su nombre, incorpora noticias de interés de todo tipo, y no sólo aquellas de carácter luctuoso, tal y como se entiende hoy en día. Ello no quita para que nos topemos con noticias que encajan dentro de esta consideración. Así observamos reseñas que hablan de delitos, muertes, accidentes, etc., tradicionalmente ignoradas por la historiografía a pesar de que por sus propias características son eminentemente sociales y nos pueden dar una información muy rica en dicho ámbito.

Ante este panorama de olvido nos hacemos las mismas preguntas que se hacía Amparo Moreno: “¿Por qué este desprecio intelectual, al extremo que unas publicaciones que suelen tener las mayores audiencias reciben la menor atención por parte de los estudiosos, incluso son ignoradas como si no existieran o, de lo contrario, son juzgadas despectivamente?" (Moreno, 1994: 35-54).

Aunque Los Sucesos va destinado primordialmente a la burguesía, las noticias de sucesos abarcan un espectro social protagonizado por clases populares, gente "sin voz", olvidada para la historia y que a través de estas páginas asoman por un instante al escenario del poder para subvertirlo en la mayoría de los casos: el suceso, se dice, "es siempre el signo de alguna derogación de una norma";

Suceso es todo lo que de alguna manera interrumpe la normalidad de una situación o un proceso. Según Auclair, los sucesos atraen porque todos, más o menos, desean la ruptura de una normalidad que les oprimen, $y$, a la vez que apaga el temor de llegar a ser víctimas de esta ruptura, al explicar que los autores de los delitos son castigados por unos agentes siempre dispuestos a imponer la ley (Ibídem).

Así, un suceso es una alteración de la normalidad, que atrae la atención del lector, y le provoca impulsos contradictorios: sensación profunda de inquietud y deseos de que la normalidad vuelva mediante el castigo a los causantes:

Mientras que la estructura narrativa típica exige la restauración final del equilibrio inicialmente roto (la causa del desorden, es decir, el agresor, que se neutraliza), éste nunca es el caso aquí. El escape del agresor mantiene el desequilibrio, introduce una suspensión en la finalización de la historia, el agente del delito siempre puede perpetuar la perturbación (Lits, 1993:116).

En Los Sucesos, apreciamos unos tímidos inicios de sensacionalismo que busca captar la atención, cosa que consigue mediante la narración de unos hechos ya de por sí atrayentes pero que, convenientemente envueltos y preparados, proporcionan un eco mayor: "lo sensaciones es así el pecado original que marca el nacimiento de la prensa moderna" (Awad, 1995: 159). El panorama de las noticias de sucesos se caracteriza por una aparición demandada por el interés que despiertan. 


\subsection{Los delitos contra las personas y los siniestros}

Que duda cabe que el mayor daño personal es la pérdida de la vida, ya sea a través del asesinato, el suicidio o el accidente, pero dependiendo de cuál sea el motivo nos permitirá valorar esta información de forma muy diferente.

Reminiscencia del Antiguo Régimen, todavía pervive entre la aristocracia la costumbre del duelo ${ }^{6}$ que normalmente trae aparejado un resultado de muerte, o como poco, de heridas graves; aun existiendo leyes en contra de esta perjudicial práctica todavía se producen, sobre todo en Europa y así se recoge en el periódico:

En un coche de primera clase de un tren que se dirigía a Bruselas se encontraron, entre otras personas, un viajero prusiano el conde $\mathrm{H}$... y el coronel austríaco, barón de B... [...] Quejose del frío el prusiano, y exigió que se cerrara la ventanilla. Si teméis el frío, dijo el austríaco obedeciendo, ya veremos luego si también os daña el fuego. [...] El duelo se verificó a pistola, a veinticinco pasos de distancia. A la señal convenida sonó un tiro, y el coronel austríaco cayó con la rodilla rota. El prusiano se retiraba ya con la sonrisa en los labios, diciendo:

-Perdonad, señores, tengo prisa, y se me escaparía el tren.

Cuando incorporándose el coronel austríaco, y apoyado en una mano, le dijo:

-Perdone V., me toca tirar; vuelva V. a su sitio.

El conde $\mathrm{H}$... palideció, pero obedeció. El barón hizo fuego, y el desgraciado prusiano, con el cráneo roto, rodó por el suelo (Los Sucesos 06/12/1867)

Noticias como ésta, aunque no se refieran a España, dan una idea de la situación de una aristocracia que ha perdido su preeminencia, y a pesar de las prohibiciones, sigue manteniendo las costumbres, sobre todo aquellas relativas al honor y orgullo.

Toda agresión, especialmente si tiene como resultado la muerte, nos está indicando la existencia de graves conflictos y tensiones. En caso de altercados, rebeliones y situaciones extremas, sólo se indica el acontecimiento producido y el número de muertos y heridos, a no ser que alguno de los fallecidos sea una personalidad que requiera el honor de individualización: "El martes fue muerto en Valencia un francés, de oficio panadero, por un dependiente de su casa, según dice un diario de aquella capital" (Los Sucesos 11/9/1867).

En una noticia así podemos destacar el hecho de que el asesinado sea francés, pues desconociendo el resto de los datos (no se da el nombre ni la nacionalidad del asesino) podemos suponer un conflicto entre nacionalidades, recelos frente al extranjero que viene a hacer negocios a España. Además, era panadero, en un momento en que el

\footnotetext{
${ }^{6}$ Para un acercamiento a la evolución de la práctica del duelo a través de las informaciones de sucesos ver: (Ortega, 2016: 269-288)
} 
pan, base de la alimentación, sufre adulteraciones y fraudes constantes. Desde la propia línea editorial se suele criticar a dichos profesionales acusándoles de que suben el precio del pan injustificadamente, señalándoles como culpables y situándolos en el objetivo de la ira popular. Asimismo es factible que estemos ante un conflicto laboral, pues es un empleado el que acaba con la vida del patrón. Escasez de informaciones que dan pábulo a los rumores e interpretaciones, pero igualmente de atrayente.

En el caso del suicidio la víctima es a la vez su propio verdugo. La incomprensión por las motivaciones es frecuente, máxime en una sociedad profundamente religiosa donde el catolicismo no contempla el suicidio como una alternativa. Si bien, cierto grado de empatía y el conocimiento de las circunstancias entre las que destacan el desamor y la situación de miseria, pueden llevar a un mínimo de empatía. En el caso de suicidio por desamor, el no poder acceder al amor de la mujer u hombre deseado es suficiente motivo como para anhelar la muerte: “Dice La Crónica Mataronesa que el sábado se encontró en el mar el cadáver de una joven. Añade el colega que, según se dice, cuestiones de amor la impulsaron al suicidio" (Los Sucesos 30/1/1868).

Siguiendo la estela de motivaciones sentimentales le siguen casuísticas como las desgracias familiares o la pérdida de alguien querido. Igualmente nos topamos con casos cuya causa indirecta es la miseria. Las malas condiciones higiénico-sanitarias multiplican la mortalidad y pueden llegar a provocar la tragedia que culmina en el suicidio: "Anteanoche a las siete se suicidó, según de público se dijo, un joven de veintitrés años, sastre, que habitaba en la calle de San Carlos, num. 11, piso 4‥ La causa de esta desgracia parece que ha sido la excitación mental que le produjo una pérdida en su familia" (Los Sucesos 06/12/1867).

La miseria y hambre que provoca la muerte en las familias es también causa de suicidio en sí misma; así, tenemos noticia de personas que ante perspectivas aciagas deciden quitarse la vida como solución rápida.

Escriben de la Rioja:

Hace pocos días que un pobre carpintero de Haro se quitó la vida, arrojándose al río Ebro. Otro vecino de un pueblo inmediato se ahorcó con un cordel. La ermita de Tironcillo, cerca de Cozcurrite, fue robada pocas noches hace, entrando el ladrón, desnudo, por un agujero tan pequeño, que apenas se comprende, y por él sacó el manto que tenía la Virgen, un rosario y una cadena de plata: el ladrón está en poder de la justicia. Últimamente, hoy ha sido reducido a cenizas el excelente edificio fábrica de harinas que extramuros de Haro, se conoce con el nombre de Ardanza (Los Sucesos 29/1/1868).

Noticias como la anterior nos hace pensar en una situación de crisis. Diversos hechos y todos relevantes como el robo de objetos sacros pertenecientes a una ermita, que dan cuenta no solo de la necesidad, sino de variaciones morales y religiosas que perturban 
las aguas tranquilas de la uniformidad religiosa. Un panorama negro que, volvemos a recordar, debemos matizar pues como es sabido, suelen ser noticias principalmente las que muestran la alteración del orden y la tranquilidad.

En cuanto a los malos tratos, aparecen con profusión. La frecuencia de episodios violentos dentro del ámbito doméstico o familiar, y los resultados terribles que exhibe, exponen una dura realidad donde la mujer ${ }^{7}$ suele salir malparada, siendo la diana del desahogo masculino ante una situación económica y laboral inaguantable. Dadas estas noticias y comentarios dispersos entre las páginas del periódico podríamos entrever, con todas las precauciones en marcha, que el maltrato es algo acostumbrado, e incluso admitido siempre que se no se lleguen a ciertos extremos.

Hace unos cuantos días se perpetró un horroroso crimen en Cabañas de la Sagra, pueblo del partido de Illescas. Estando maltratando a su esposa un vecino, acudió a los gritos el alcalde, quien, al llamar a la puerta, sólo obtuvo por contestación insultos y amenazas. Al fin abrió aquel desalmado, y armado de un cuchillo de grandes dimensiones, dio muerte al alcalde, hundiéndole el arma en el vientre. El agresor huyó inmediatamente, y el juzgado de Illescas se constituyó en dicho pueblo para instruir las diligencias oportunas (Los Sucesos, 16/1/1868).

En la noticia se ve como la intervención del alcalde ante un caso de maltrato causa su muerte. El hecho de que fuera el alcalde el que acudiera ante el reclamo de los gritos de la mujer maltratada puede indicar tanto que fuera la persona más cercana, como que el resto del pueblo no se metiera en estos asuntos por miedo, por ser algo privado, algo corriente. Además, es una figura de mando que se cree con la capacidad para intervenir, a la vez que como representante local de la autoridad fortalece el interés por los hechos.

“Querellábase una mujer ante el juez de los malos tratamientos de su marido. -¿`Y qué pretexto toma para castigaros? Preguntó el juez. -Señor, contestó ella: no toma pretexto; lo que toma es una vara de acebuche" (Los Sucesos, 25/1/1868). Destaca en la noticia anterior la utilización del término castigaros, pues el juez presupone la culpa de la mujer, la existencia de una causa que justifica el hecho del mal trato. La respuesta de la mujer es a la vez inocente y muy dura, indicando que no hay motivo ninguno para la agresión. Reseñas de este tipo demuestran el grado de penetración en la mentalidad de la época de los malos tratos como algo habitual y que puede estar justificado según que casos.

Ayer mañana, entre diez y once, ocurrió una desgracia en la calle de la Comadre, núm. 43. Habitaba en dicha casa una mujer llamada A. J., la cual, según

\footnotetext{
${ }^{7}$ Un breve acercamiento a la cuestión de los malos tratos a través de la información de sucesos en un momento histórico posterior puede consultarse en: (Ortega, 2012: 1-14)
} 
públicamente se ha dicho, sostenía relaciones amorosas con A. C., ejecutor de sentencias de la real audiencia de esta corte. Este parece que fue a visitar sobre las nueve de la mañana a A., y al poco tiempo salió ensangrentada de su habitación pidiendo auxilio. La infeliz tenía cuatro heridas en el cuello y otra en el costado, y los vecinos designaban a C. como autor de las lesiones. Los guardias veteranos $\mathrm{y}$ el inspector del distrito acudieron inmediatamente al sitio de la ocurrencia, trasladando a aquella a la casa de socorro de la plazuela del Progreso, y de allí al hospital general.

El juzgado de guardia empezó en el acto a instruir las oportunas diligencias. El presunto agresor parece que se halla preso (Los Sucesos, 7/3/1868).

Para terminar este apartado nos acudimos a los accidentes, con resultados variables al igual que sus causas, pues tanto pueden provocar heridas leves como causar la muerte. En general, la mayoría de los numerosos accidentes que se recogen en sus páginas evidencian una situación de precariedad laboral. Deducimos la existencia de inadecuadas condiciones de trabajo, pocos medios, trabajo a destajo, instalaciones paupérrimas, en fin, nos confirma la existencia de miseria en pleno desarrollo de la revolución industrial:

Al llegar el tren de mercancías del miércoles al kilómetro 53 de la línea del Norte, tuvo que detenerse a causa de haber un obrero muerto sobre la vía. Se supone le mató el tren exprés, que había pasado momentos antes. La autoridad local se constituyó inmediatamente en el sitio de la ocurrencia (Los Sucesos, 20/12/1867).

O este otro:

La semana anterior falleció uno de los operarios ocupados en los trabajos de la carretera de Murcia a la villa de Berga, en el punto llamado del Grapal, a consecuencia del desprendimiento de una roca que, deseando quitarla del punto en que se hallaba, se le cayó encima, mutilándole conforme es de presumir (Los Sucesos, 12/12/1867).

En cuanto a los accidentes en las obras de acondicionamientos de las redes viarias, las pésimas condiciones laborales, unidas a la proliferación de las vías férreas y la especulación, provocan el aumento de los siniestros. Igualmente se producen accidentes de ferroviarios en una red que aún no existía en sus mejores condiciones de aprovechamiento, ni de rentabilidad, ni menos aún de seguridad tanto en el trazado como en el uso. Como es sabido, al comenzar la segunda mitad del siglo XIX apenas se había comenzado a construir la red de ferrocarriles españoles pero el gobierno va a promover una construcción ferroviaria frenética: "la Ley de Ferrocarriles de 1855 y las leyes bancarias de 1856 eran excepciones a las reglas restrictivas generales de 1848 . El efecto que produjeron estas cuatro leyes combinadas fue el de dirigir los recursos del 
país hacia la construcción ferroviaria en detrimento de los demás sectores económicos" (TORTELLA, 1975: 170). Y dadas las circunstancias de premura, especulación y malas condiciones laborales, proporcionaban frecuentes noticias relacionadas con accidentes en su construcción o uso.

El lunes último, entre las estaciones de Pozaldez y Valdestillas, en la vía del Norte, fue atropellado por la locomotora un guarda que intentó salvar un carnero que se hallaba en medio del camino (Los Sucesos, 6/11/1867).

Asimismo se producían incendios en edificios tanto públicos como viviendas particulares. No había un sistema de extinción estable y eficaz como en otros países, basándose el apagado del fuego en la cooperación de los vecinos.

A las tres de la tarde del día 2 se declaró un violento incendio en el convento de Carmelitas de Sariñena. El fuego empezó por una chimenea, y con la violencia del viento se propagó instantáneamente a todo el tejado; de manera que a la hora era todo él una inmensa hoguera. Las monjas se salvaron refugiándose en las casas de algunos amigos suyos. El pueblo en masa, con la autoridad local, en unión de la guardia civil, acudió a remediar el siniestro, pero no pudieron sus esfuerzos ser coronados con éxito satisfactorio, porque el fuerte cierzo que reinaba imposibilitaba cuanto se intentaba hacer.

Al fin, después de mucho trabajar y con mucha exposición, pudo cortarse el tejado e impedir que se propagase al de la iglesia del mismo convento. Duró el fuego catorce horas, y la suerte ha sido que el edificio está aislado y extramuros de la población. El edificio ha quedado completamente desmantelado é inhabitable (Los Sucesos, 7/12/1867).

Y este otro ejemplo:

El sábado a las nueve ocurrió un incendio en la calle del Príncipe, núm. 40, y en la calle de Atocha, núm. 72, se declaró otro un poco más tarde, pero ninguno de estos tomó proporciones, pues las cuadrillas de policía urbana lograron sofocarlos (Los Sucesos, 7/12/1867).

También existen accidentes que no tienen una causa determinada, aunque puedan existir condiciones que los favorezcan como el mayor número de personas en las ciudades. Además, el desplazamiento de un número mayor de gente, el aumento del tráfico tanto de personas como de carruajes, su difícil convivencia en la ciudad, aumenta las probabilidades de que sucedan:

El lunes a las nueve y media bajaba a escape por la calle de la Montera la berlina de alquiler núm. 485, y al llegar a la Puerta del Sol se cayó el caballo, lanzando 
del pescante y a gran distancia al conductor. Trasladado a la inmediata casa de socorro, fue curado de sus heridas y contusiones (Los Sucesos, 12/12/1867).

Accidentes en lugares de trabajos como las minas llaman la atención por la magnitud de la catástrofe, con consecuencias gravísimas para numerosas personas ya sean víctimas directas o familiares. Estos desastres indican la carencia de una técnica extractiva adecuada, y en general la falta de seguridad laboral que sumado a las malas condiciones laborales y falta de buena alimentación, hacen que trabajos como el de la mina ocasionen multitud de heridos y muertos.

Tenemos que comunicar a nuestros lectores la noticia de una terrible catástrofe ocurrida anteayer en la mina Santa Elisa, perteneciente a la sociedad titulada Fusión carbonífera de Espiel y Belmez.

Hallábanse en dicha localidad los señores marqueses de Casa Larios y de Casa Loring, con el objeto de hacer un negocio en carbones, producto de aquella ricas cuencas, y se disponían a bajar a las galerías de la mina Santa Elisa, cuando un hundimiento instantáneo de terreno dejó sepultados bajo sus escombros a 34 infelices trabajadores.

Los Sres. Larios y Loring se salvaron milagrosamente.

Lamentamos profundamente esta desgracia, que tantas lágrimas estará costando a un gran número de familias (Los Sucesos, 6/4/1868).

La noticia continúa en los siguientes ejemplares:

Según dice El Guadalquivir de Córdoba, ascienden a más de 60 los cadáveres extraídos de la mina Santa Elisa, por consecuencia del siniestro de que ya tienen conocimiento nuestros suscriptores (Los Sucesos, 14/4/1868).

\subsection{Los delitos de falsificación, contra la propiedad y de salud pública}

La picaresca se lleva a cabo en el ámbito cercano, destacando la adulteración y el fraude alimenticio. No era el delito económico el elemento principal, sino las posibles consecuencias para la salud pública cuando de alimentos se trataba, como demuestran los casos de intoxicación de varias personas por el consumo de diversos productos. El pan, base de la alimentación, especialmente entre la clase popular, se prestaba a este tipo de fraude. Las falsificaciones [adulteraciones] se extendían a todo el espectro imaginable de productos como por la harina, esencia de almendras y un largo etcétera. Si bien el más relevante es el chocolate. Lo cual nos da una idea de la extensión de su consumo y la repercusión de éstas. 
Los productos más exóticos se prestaban con facilidad a la adulteración al ser casi imposible la comparación con el original. En este aspecto, la prensa actúa como un servicio público informando de las continuas falsificaciones que se descubren. Problema y solución, esta es una característica de los artículos que encontramos en Los Sucesos. Así, si es posible, cuando se da una noticia de falsificación de un producto alimenticio se trata de dar un método para identificar la compra con un mínimo de garantías.

Dejando a un lado la adulteración en los alimentos, destaca la existencia de personas que falsean monedas y sellos, así como papel oficial con valor económico. El sistema monetario desordenado, sumado a la dificultad de localización de falsificaciones y detención de autores, permite una alta frecuencia de dichos delitos, y por ello, resulta útil formular indicaciones sobre descubrimientos relacionados con la puesta en circulación de moneda o sello falso.

Habiendo sido falsificados los sellos de correos de 50 milésimas, se han adoptado por la dirección las medidas más eficaces a evitar su circulación, y conseguir se descubran los autores de tan punible delito.

Las diferencias más notables que existen entre los sellos falsos y los legítimos son las siguientes:

La letra E en la palabra Correos, es más pequeña en los falsos que en los legítimos.

El adorno que hay entre la palabra España y escudo consiste en los legítimos en cuatro círculos distribuidos alrededor de otro círculo central, y en los falsos no son círculos, especialmente el del centro, sino una elipse muy pronunciada, y mucho más grande que en los legítimos.

El ojo de S. M. en los falsos está mucho más abierto.

La nariz del retrato es en los falsos más corta y redonda.

El labio superior del retrato es en los falsos mucho más corto.

En el trepado de los falsos hay bastantes agujeros sin perforar (Los Sucesos, 14/1/1868).

Otro ejemplo en la provincia de Zamora:

En la villa de Benavente, provincia de Zamora, han sido ocupados dos cuños para fabricar moneda falsa, habiéndose preso a cierto sujeto con tal motivo (LoS Sucesos, 13/6/1868).

Y en Barcelona 
La policía de Barcelona ha logrado apoderarse de tres máquinas, una de ellas hidráulica, que estaban destinadas a la fabricación de moneda falsa, ocupando infinidad de piezas de medio real, de 2 y de 4 rs., varios troqueles y metales recortados. También se ha apresado a los falsificadores, entre los cuales se encuentra un grabador a quien se le ocupó un cuño que llevaba en el bolsillo del pantalón (Los Sucesos, 17/6/1868).

Por último, hemos de mencionar noticias varias, también numerosas sobre ladrones, hurtos, robos a mano armada, etc. En principio las causas e implicaciones sociales que podemos colegir son las mismas que en el caso de timos y otros sucesos: la miseria generalizada provoca delincuencia orientada a obtener de manera ilegal lo que legalmente no logra. No extraña que, además, existan otras informaciones sobre la actuación policial y de la autoridad; ${ }^{8}$ así como de la creación de nuevos cuerpos, como la Guardia Rural, con el fin de atajar la inseguridad.

Escriben de Cazorla que en la noche del 21 fue robada la iglesia parroquial de Peall, en aquel partido, llevándose los ladrones cuantas alhajas había en el templo. Constituido al día siguiente el juzgado en el lugar del delito, pudo apresar a los presuntos autores del robo, entre los que se encuentra el mismo sacristán de la iglesia (Los Sucesos, 28/12/1867).

En Los Sucesos de 5 de enero de 1868 se podía leer:

El día 30 fue detenido por dos enmascarados cerca del Mas Rabassa, un carro que había salido de Torredembarra a las cinco de la mañana, en el que iba un joven carretero con su padre muy anciano ya, que se dirigían a Reus para compras.

Los encubiertos, navaja en mano, acometieron a aquellos infelices, los que, gracias a su serenidad y valor quedaron vencedores, después de una lucha encarnizada, de la que resultó levemente herido en el brazo el joven carretero, y uno de los agresores de un hachazo, con cuya arma se defendía el pobre anciano, obligando así a los enmascarados a desistir de su empeño y buscar en la huida su salvación.

La cantidad, que llevaban consigo aquellos bizarros campesinos se hace ascender a cinco mil reales.

Pocos días antes de este suceso, fue acometido en el mismo punto, un jinete, que debió su salvación al corcel en que cabalgaba.

\footnotetext{
${ }^{8}$ La presencia de la autoridad y el castigo a los culpables es un elemento esencial en el entorno de las informaciones que estamos trabajando. Ofrecen una imagen potente de la capacidad del sistema de poder como garante del restablecimiento del orden quebrado. Sobre esta temática, para la época de la Restauración, pueden consultar: (ORTEGA, 2017: 733-744).
} 
Y en Los Sucesos de 9 de enero de 1868:

En una de las calles más públicas de Granada se ha cometido el robo de seis bueyes. Se conoce que los ladrones no tenían miedo a los cuernos. Nunca habíamos tenido notica de un robo de esa especie.

Más impactacte es la noticia publicda en Los Sucesos el 17 de enero de 1868:

De Fuente el Saz escriben, con fecha 12 del actual, los siguientes pormenores del robo verificado en aquel pueblo en la madrugada del día 10 del corriente.

Los ladrones, en número de treinta, entraron en el pueblo a las dos de la madrugada del referido día, y penetraron en la casa de Marcos Martín, vecino bastante acaudalado de aquel pueblo, arrancando una ventana. Una vez dentro, trabóse una lucha cuerpo a cuerpo, de la cual resultó muerto Santiago Martín, yerno del anterior, el Marcos herido de gravedad en el vientre, y un criado también de tanta gravedad, que se cree morirá. Otro hijo político del Marcos, que acudió en los primeros momentos, consiguió matar a uno de los ladrones y herir gravemente a otros.

No obstante, la resistencia, los ladrones consiguieron llevarse unos 12.000 duros.

En cuanto se tuvo conocimiento en Madrid de este hecho, dispuso el señor gobernador de la provincia que saliesen fuerzas de guardia civil, en persecución de los criminales, habiendo conseguido ya prender a unos diez o doce.

Parece que algunos de los agresores eran vecinos de Fuente el Saz y de los pueblos inmediatos.

La guardia civil continúa una viva persecución contra el resto de la partida. Hasta ahora no se ha podido rescatar dinero alguno.

La última noticia parece mostrar algo más que un ataque contra un terrateniente, ya que el elevado número de participantes de los alrededores podría indicar una acción subversiva contra un potentado local. Igualmente observamos como la Guardia Civil se erige en útil herramienta para mantener el orden público destacando entre sus múltiples funciones las de protección de la propiedad privada:

...la defensa de la propiedad es una función básica de la Guardia Civil. En realidad, constituye un correlato de la lucha contra el bandolerismo y es fuente de no pocas dificultades para os guardias cuando han de detener a los desheredados que han hurtado bienes propiedad de los acomodados. En tales situaciones, vocablos como 'pobre', 'rico', 'verdugo'... se cargan de significado amenazador y siniestro, y en los juicios peyorativos la institución lleva la peor 
parte, pues pasa por ser la mantenedora del orden que beneficia a los económica y socialmente pudientes (JOVER, 2005: 757).

En Los Sucesos tenemos varios ejemplos como la noticia publicada el 26 de enero de 1868:

Han sido presos ocho o diez de los presuntos autores de la detención en el túnel de la Brújula, cerca de Quintanapalla, del tren del ferrocarril del Norte, en que se creía enviaba el gobierno 50.000 duros.

Esta captura, y la de 17 forajidos en Zarraton de Rioja, han calmado la alarma en que allí vivian los vecinos pacíficos, temerosos de verse sorprendidos de un momento a otro.

O este otro publicado en Los Sucesos el 3 de abril de 1868:

La industria rateril no es de las más atrasadas en España. Como demostración, allá va lo siguiente, cuya inserción se nos ruega, y nosotros a nuestros colegas lo hagan saber a sus lectores por lo que pueda interesarles:

"Ha vuelto a parecer el ingenioso caco que, con el nombre de Vicente, y a pretexto de traer encargos de familia, sorprendió a muchos el año pasado. Las señas de este tuno son: Estatura regular, color moreno, delgado de cara, algo picado de viruelas y barba corrida; viste de levita, y conserva la costumbre de decir que vive en la plaza de Isabel II, núm. 7; las mismas señas que daba el año pasad a cuantos robaba. Recomendámoslo a los dependientes de la autoridad".

\section{Conclusiones}

El estudio de una fuente tan diversa y rica, enmarcada en un periodo de la historia de España tan interesante nos proporciona nueva información para entender mejor dicho momento histórico. La investigación se ha centrado en la historia social y tangencialmente en la historia de la prensa. Respecto a la primera hemos percibido un periódico encuadrado dentro de lo que se ha dado en llamar prensa moderna se erige como entretenimiento y servicio público destinado a la familia burguesa.

Con todo, el trasfondo de mayor relevancia es la cuestión social, pues era un factor de inestabilidad que iba en contra de los intereses burgueses. Uno de los principales problemas, omnipresente para las clases bajas, es el de la alimentación, que es arduo tanto por el precio de la comida (crisis de subsistencia, especulación, bajos sueldos, etc.) como por la adulteración, que provoca fraude y daños físicos en los casos más graves. 
El análisis de las noticias de sucesos cuyos principales protagonistas son precisamente las clases tradicionalmente alejadas del foco de la historia, facilita una mejor compresión de este panorama general. Nos topamos con una sociedad necesitada, que no vive en las mejores condiciones y se encuentra tensionada, como se advierte al estudiar los asesinatos y los suicidios que se suceden en las páginas de los diarios. Ante este horizonte hay quien opta por el pillaje y la delincuencia, ya sea a través de la adulteración de alimentos, timos o robos, ante los cuales el periódico actúa como altavoz preventivo y denunciante. Obviamente no es una mayoría social la que aquí se ve reflejada sino aquellos que al margen de cuestiones morales se ven impelidos al delito y no ven otra solución a su situación personal. No podemos dudar de que una mayoría de la población vivía conforme a la legalidad y trataba de seguir adelante siguiendo dicha vía, incluso cuando su situación se advertía extrema, pues si no estaríamos ante un nivel de tensión social aún mayor del que ya se ve reflejado en las páginas de la prensa contemporánea.

Emerge desde las páginas analizadas la existencia de malos tratos en el ámbito familiar, tanto a niños como especialmente a mujeres. Su lectura nos inclina a pensar en una sociedad permisiva hasta cierto punto, lo cual no puede asegurarse categóricamente sólo con las fuentes aquí estudiadas. No son informaciones ocultadas pero tampoco exageradas. Si parece entreverse cierto rechazo a actuar cuando una realidad así aparece en el círculo más próximo, más por el temor de meterse en asuntos privados que no le incumben que por considerar dichos actos como algo cotidiano y aceptado. El hecho de que la persona que se inmiscuyera, cuando se detectaba unos actos de ese estilo, arriesgara su propia integridad personal, podía frenar los impulsos de ayuda a la persona maltratada. Además, la lectura de sucesos en que aquel que ha intervenido en un caso similar ha resultado gravemente herido o muerto, desalienta posibles intervenciones.

\section{Referencias bibliográficas}

ALONSO, C. (2002): “Ángel Fernández de los Ríos (1821-1880). La escritura militante", en: ORTEGA, M.-L. (Ed.): Escribir en España entre 1840 y 1876, Madrid, Visor, pp. 139-162.

AWAD, G. (1995): Du sensationnel. Place de l'événementiel dans le journalisme de masse, París, L'Harmattan.

BAHAMONDE MAGRO, A. y TORO MÉRIDA, J. (1978): Burguesía, especulación y cuestión social en el Madrid del siglo XIX. Madrid, Siglo XXI. 
CASASÚS, J. Mạ. (1998): Ideología y análisis de los medios de comunicación, Barcelona, CIMS 97.

CAPELLÁN DE MIGUEL, Gonzalo, (2010): “La opinión secuestrada. Prensa y opinión pública en el siglo XIX”, Berceo, 159, pp. 23-62.

CRESPO SÁNCHEZ, F. J. (2016): Crear opinión para controlar la opinión. Ideología, sociedad y familia en el siglo XIX, Madrid, Doce Calles.

DEL Río, C. (2016): Fernández de los Ríos. Biografía breve, Madrid, Ediciones 19.

GARCIA GALINDO, J. A. (1995): Prensa y sociedad en Málaga 1875-1923. La proyección nacional de un modelo de periodismo periférico, Málaga, Ediciones Edinford.

GUEREÑA, J. L. (1982): "Las estadísticas de la prensa (1867-1927)" en AA.VV: Metodología de la historia de la prensa española, Madrid, Siglo XXI, pp. 81-118.

HARTZENBUSCH, E. (1993): Apuntes para un catálogo de periódicos madrileños desde el año 1661 al 1870. Reproducción facsímil de la ed. De Madrid Sucesores de Rivadeira 1894, Madrid, Biblioteca Nacional, 1993.

JOVER ZAMORA, J. Mạ. (2005): La era isabelina y el sexenio democrático. Tomo II, Madrid, Biblioteca Historia de España RBA Coleccionables.

LITS, M. (Coord.) (1993): La peur, la mort et las médias, Bruxelles, Editions Vie ouvrière.

MORENO SARDÀ, A. (1994): "Premsa de successos: models de marginació i integració social en els processos de mobilitat social" en Anàlisi, vol no 16, pp. 35-54.

ORTEGA MUÑOZ, V. J. (2012): "La violencia contra la mujer durante la Restauración a través del tamiz periodístico: La Unión Mercantil" en Revista de Claseshistoria, mayo de 2012, artículo 300, págs. 1-14. Disponible en Internet (05/12/2017): http://www.claseshistoria.com/revista/2012/articulos/ortegaviolencia.pdf

- (2014) "Historia de la comunicación y solidaridad: las noticias de catástrofes naturales en la prensa de la Restauración" en GARCÍA LÓPEZ, Marcial, GARCÍA GALINDO, Juan Antonio y HUERTA FLORIANO, Miguel Ángel (coords.): El papel de la Universidad en los procesos de comunicación y cooperación para el desarrollo social y humano. Madrid, Fragua, pp. 509-520.

- (2016) "Honor, venganza y construcción social del delito en la prensa de la Restauración" en Clío \& Crimen, 13, pp. 269-288. Disponible en Internet (05/12/2017): http://www.durangoudala.net/portalDurango/RecursosWeb/DOCUMENTOS/1/2_10581_6.pdf 
- (2017) "Representación del castigo en las noticias de sucesos durante la Restauración: autoridad y cárcel como elementos disuasorios" en GONZÁLEZ MADRID, Damián A., ORTIZ HERAS, Manuel y PÉREZ GARZÓN, Juan Sisinio: La Historia, lost in translation? Actas del XIII Congreso de la Asociación de Historia Contemporánea. Cuenca, Universidad de Castilla-La Mancha, pp. 733-744. Disponible en Internet (05/12/2017): http://publicaciones.uclm.es/la-historialost-in-translation/

- (2018) iExtra, extra! Poder, información y control de la sociedad española en las noticias de sucesos, 1881-1923, Zaragoza, Pórtico.

RODRÍGUEZ CÁRCELA, R. Mạ. (2016): “La prensa de sucesos en el periodismo español” en Revista Internacional de Historia de la Comunicación, 2016, 6, pp. 22-44. Disponible en Internet (05/12/2017): http://institucionales.us.es/revistarihc/rihc06-completo.pdf

-- (2011) "La información de sucesos. Temática en prensa escrita", en Correspondencias \& Análisis, 2011, artículo 300, págs. 309-325. Disponible en Internet (05/12/2017):

https://dialnet.unirioja.es/descarga/articulo/3934228.pdf1

SEOANE, Mạ. C. (1977): Oratoria y periodismo en la España del siglo XIX, Valencia, Castalia/Fundación Juan March.

TORTELLA CASARES, G. (1975): Los orígenes del capitalismo en España, Madrid, Editorial Tecnos.

TUÑON DE LARA, M. (1973): Metodología de la historia social de España, Madrid, Siglo XXI. 